\title{
A Programmable, Multiple Supplement Cattle Feeder for Pasture Use
}

\author{
R. S. Thomas, D. R. Buckmaster
}

\begin{abstract}
A mobile, programmable, multiple supplement cattle feeder for pasture use was designed, constructed, and evaluated. The feeder is capable of feeding an individualized ration of liquids and solids to cattle in a grazing system without the need for AC power in a research pasture setting. The feeder is electrically powered by solar energy (with battery backup). Additional energy is stored in the form of compressed air held in two 53-L (13.5-gal) tanks, which must be charged by an external source. The design includes storage and metering equipment for up to five separate feed ingredients. Two pressure tanks with approximately 115-kg (254-lb) capacity are provided for fats or molasses-based liquid supplements; two small bins with approximately 40-kg (88-lb) capacity are provided for small quantities of solids, and one 1.2- $\mathrm{m}^{3}\left(42-\mathrm{ft}^{3}\right)$ bin is provided for grain concentrates. Animal identification is achieved using radio transponder ear tags, and control is handled through the use of a programmable logic controller.

A mixed group of 10 dairy heifers and cows were used to complete testing. Animals adapted readily to feeder use after initial training and no problems were encountered with tag reading. Liquids, grains, and small-specialized solids were all metered accurately and consistently (coefficient of variation was $0.45 \%$ for liquids, $5.8 \%$ for small solids, and $2.3 \%$ for large solids) based on an individual animal program. Though effective for delivering molasses-based feeds, air leaks in the liquid-metering system required constant monitoring. Computer simulation of the power system suggests that it should handle supplemental feeding of up to 20 grazing dairy cows at a central Pennsylvania location.
\end{abstract}

Keywords. Feeding system, Cattle feeding, Pasture, Grazing, Solar power.

$\mathrm{F}$ eed costs represent a substantial portion of the total cost of producing meat and dairy products. As production performance levels of modern farms continue to increase, the importance of animal nutrition also increases. It is important for each individual animal to receive the correct nutrient balance for its specific situation. For financial and herd health reasons, the animals should not be free to over-consume expensive or potentially toxic concentrates. The need for feeding supplemental nutrients to cattle in a grazing system is well established. To the extent that concentrates complement grazed forage, supplementation is economical (Earley et al., 1999; Soder and Rotz, 2001). However, due to the substitution effect, excessive feeding of concentrates can actually decrease utilization of grazed forages (Mayne, 1991).

Stockdale et al. (1987) studied the effects of feeding high-energy supplements to pasture-fed dairy cows. The

Article was submitted for review in October 2002; approved for publication by the Information \& Electrical Technologies Division of ASAE in May 2003.

Trade names are used solely to provide specific information. Mention of a trade name does not constitute a warranty of the product by The Pennsylvania State University or an endorsement of the product to the exclusion of those not mentioned.

The authors are Roderick S. Thomas, Engineering Associate, and Dennis R. Buckmaster, ASAE Member Engineer, Associate Professor, Agricultural and Biological Engineering Department, Pennsylvania State University, University Park, Pennsylvania. Corresponding author: Roderick S. Thomas, 249 Ag. Engineering Building, University Park, PA 16802; phone: 814-865-2262; fax: 814-863-1031; e-mail: rst5@psu.edu. results were dependent on stage of lactation, rumen ammonia level, and amount and type of supplement fed; however, the general conclusion was that any competitive system with a high level of pasture utilization involves supplemental feeding. Even if ideal pasture conditions could be maintained throughout the grazing season, energy supplementation is needed by high-producing dairy cows, particularly during the first half of lactation (Muller, 1993). Adjustments are needed to the pasture supplement as pasture quality and pasture availability vary (Hoffman et al., 1993; Earley et al., 1999; Leaver, 1982); a system that can provide a proper blend is needed (Stockdale et al., 1990).

The solution for some farming systems has been a computer-controlled feeder. In the United States, computercontrolled feeders that identify individual animals and provide programmed feed rations have been used since about 1980. Most systems use either a neck or ear tag to identify the animal. The tags can be of the passive (responder), active (transponder), or infrared scanning type (Weber, 1989). Commercial use of feeding computers has been limited to stationary feeding in or near structures with readily available $\mathrm{AC}$ electrical power. These units are typically programmed with the number of feeding periods spaced throughout the day and night, the animal identification tag number, stage of lactation, the individual animal's allotted ration, and other herd health and management data.

The currently available computer feeding systems are most effective when animals are near the barn for most of the day, which is not the case with beef or dairy herds extensively utilizing grazed pasture. Unless free choice supplements were made available, dairy cows would only have the opportunity to consume supplements two or three times a day 
around milking time, and beef animals left in remote pastures would have no opportunity to consume supplements. These practices are contrary to recommendations by Shrestha et al. (1983) who reported that a feeding system providing numerous smaller meals of concentrates throughout the day and night has the potential to increase efficiency of nutrient utilization because of reduced variation in the fermentation pattern. Pitt and Pell (1997) agree that more small meals yield more steady rumen conditions; the lower $\mathrm{pH}$ fluctuation leads to less milk fat depression. A potential method for providing supplements to grazing animals is a computerized feeder with mobile capabilities since feeding behavior can be controlled by the feeding routine (Livshin et al., 1995). Albright (1993) suggested that computerized dispensing of concentrates (in non-grazing situations) could economize on consumption when feeding of different rations is impossible; likely it can improve feeding economics in grazing situations, also.

Recognizing the importance of rotational grazing systems, Gardner et al. (1995) extended the use of computer feeding to a mobile, pasture application. They developed and tested a mobile computer-controlled feeder capable of supplying a ground grain mix to lactating dairy cattle in a rotational grazing system. The system had a $2500 \mathrm{~kg}$ capacity grain bin and auger controlled by a Farmtronix ${ }^{\mathrm{TM}}$ computer. Animal identification was achieved using a Farmtronix ${ }^{\mathrm{TM}}$ identification unit and neck tag transponders. Power (in part) was provided by photovoltaic cells and a bank of storage batteries. The DC power provided by the solar cells and batteries was converted to $115 \mathrm{VAC}$ and fed to the computer and auger motor. Power generated averaged $700 \mathrm{~W}-\mathrm{h} / \mathrm{d}$ while consumption was at a level of $1900 \mathrm{~W}-\mathrm{h} / \mathrm{d}$. Although the system was not efficient enough to run without additional electrical power, Gardner et al. (1995) concluded that photovoltaics could power such a feeder if redesigned for higher efficiency. Hongerholt et al. (1997) used this system and showed that a mobile, computer-controlled concentrate feeder can successfully feed dairy cattle in a rotational grazing system. They found that the computer-controlled feeder led to less grain consumption with similar fat-corrected milk production. These results, combined with evidence that liquid supplements can be economical in grazing situations (Earley et al., 1999), point to a need for a feeder which can dispense controlled blends of liquid and solid supplements to grazing animals.

\section{OBJECTIVES}

The objectives of this project were to:

- Design, construct, and evaluate a mobile feeder with efficiency high enough to be operated without the need for $\mathrm{AC}$ power in a research pasture setting.

- Develop the capability to meter liquids (including molasses) and very small quantities of specialized feed supplements in addition to grain concentrates.

\section{FeEDER DESign \\ DESIGN OVERVIEW}

The feeder is mounted on a wagon and capable of feeding up to five separate feed ingredients including a primary grain concentrate, two liquids (such as fat or molasses-based supplements), and two small pelletized or granular feeds

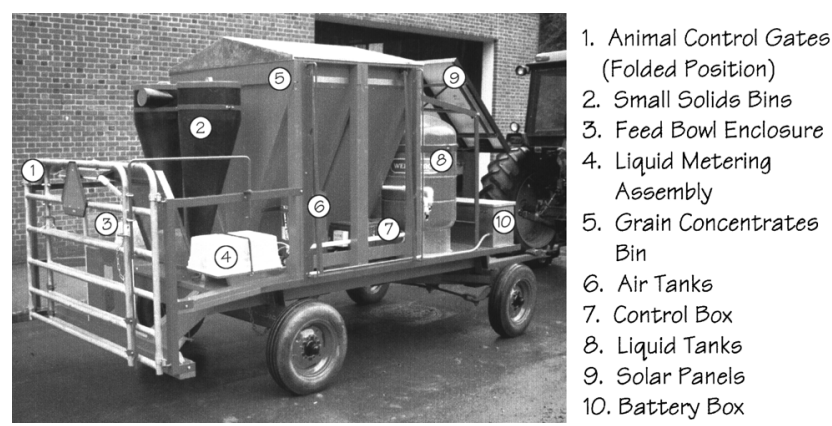

Figure 1. Feeder major component locations.

(fig. 1). All feeds are delivered to a common feed bowl with no prior mixing. The rate of feed delivery is approximately the same as the animals' consumption rate; this way, the amount of feed left in the bowl is limited should the animal back out before finishing its allotment. Each individual animal receives a programmed volume of each feed ingredient based on its need. While the amount of feed can be different for each animal, the number of feeding periods per day is common to the entire group. Electrical power is generated by solar panels mounted on the front of the wagon, which are used to charge a bank of batteries providing power during periods of darkness and cloudy skies. Electrical power is supplemented by fluid power in the form of compressed air used in the metering of liquid feeds. Each animal carries a radio transponder ear tag that relays a tag number to a Programmable Logic Controller (PLC) via a reader and interface system. The PLC retains the program information, controls all feeding operations, and records feeding data.

A mobile chassis was selected for several reasons. First, it allows the feeder to be used in more than one paddock regardless of the pasture layout. This level of mobility is particularly useful in a rotational grazing system. Secondly, by moving the feeder to different locations the amount of trampling damage and manure concentration in the vicinity of the feeder is minimized. The feeder can be filled at feed storage locations, which may minimize the need to transfer feed from one vehicle to another.

Equipment was mounted such that weight is approximately evenly distributed over the four corners of the wagon. The galvanized steel battery compartment is mounted in the front of the wagon with the two liquid tanks mounted just behind. The solar panels are mounted above the batteries and liquid tanks. The large grain concentrate bin is just behind the liquid tanks. The two vertical bins behind the large grain bin are used to hold the small granular or pelleted feeds. The feed bowl and animal control gates are at the rear of the wagon. Various barriers have been included to deter curious animals from damaging or interfering with the feeder.

The gates fold flat against the back of the feeder for transportation and storage. When set up in the pasture, the gates are unfolded and fixed in position by a combination of braces (fig. 2). The gate opening is $80 \mathrm{~cm}$, approximately the width of a Holstein cow, while the fixed end is spread wide at the wagon corners. This width keeps the tags of other adjacent cows from getting too close to the transponder reading antenna, which could confuse the control system. The animals enter the feeding area directly from the rear between the gates and move forward toward the feed bowl, which is partially protected from the weather by a galvanized 


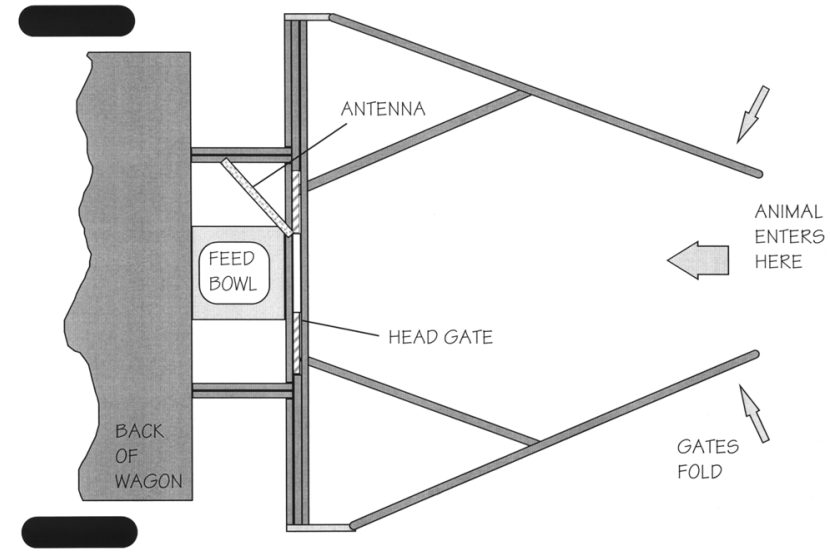

Figure 2. Diagram of animal control gates.

steel cover and lexan side panels. In order to reach the feed bowl, the animal must place its neck between stationary head gates. The gates ensure that the head is positioned to promote good tag reading while allowing plenty of free movement and a natural feeding position. Since the feed bowl is mounted close to the ground, it is designed to pivot upward if it strikes an obstacle.

\section{Electrical Power System}

The feeder was designed with mobility in mind, so an AC power line would not be a suitable source of power. Solar panels with battery backup were used to supply electrical energy needs (fig. 3). The solar panels are mounted on a structure that allows adjustment from approximately 10 degrees to completely vertical. The system is divided into two parts; a 12 VDC bank, and a 24 VDC bank. The 12 VDC portion consists of two 6-V deep cycle "golf cart" batteries. The batteries are model GC-5 manufactured by Exide and have a $226 \mathrm{~A}-\mathrm{h}$ capacity. The batteries are charged by a single $60 \mathrm{~W}$ solar panel model MSX-60 manufactured by Solarex Corporation; charge regulation is controlled by a Sun Selector model 1325-M4. The Sun Selector unit is specifically designed for solar charging and can handle up to 4 amps continuous charge current, with a charging efficiency of about $95 \%$. The regulator functions by diverting full current to the batteries when charge state is low, then pulses current as the batteries become fully charged. This reduces plate oxidation and therefore prolongs the life of the batteries. The $24 \mathrm{VDC}$ system is similar to the $12 \mathrm{~V}$ system, however four GC-5 batteries make up the bank and two $56 \mathrm{~W}$ (Solarex MSX-56) panels supply the charge current. Charge regulation is handled by a Sun Selector model 1405-M4 controller, which is identical to the $12 \mathrm{~V}$ model but made to operate at $24 \mathrm{~V}$.

\section{LIQUID METERING}

The feeder has the capacity for two separate liquid feeds. Both liquid metering systems are identical. The feed is stored in an Amtrol Inc. Model WX-302 326-L (86-gal) bladder-

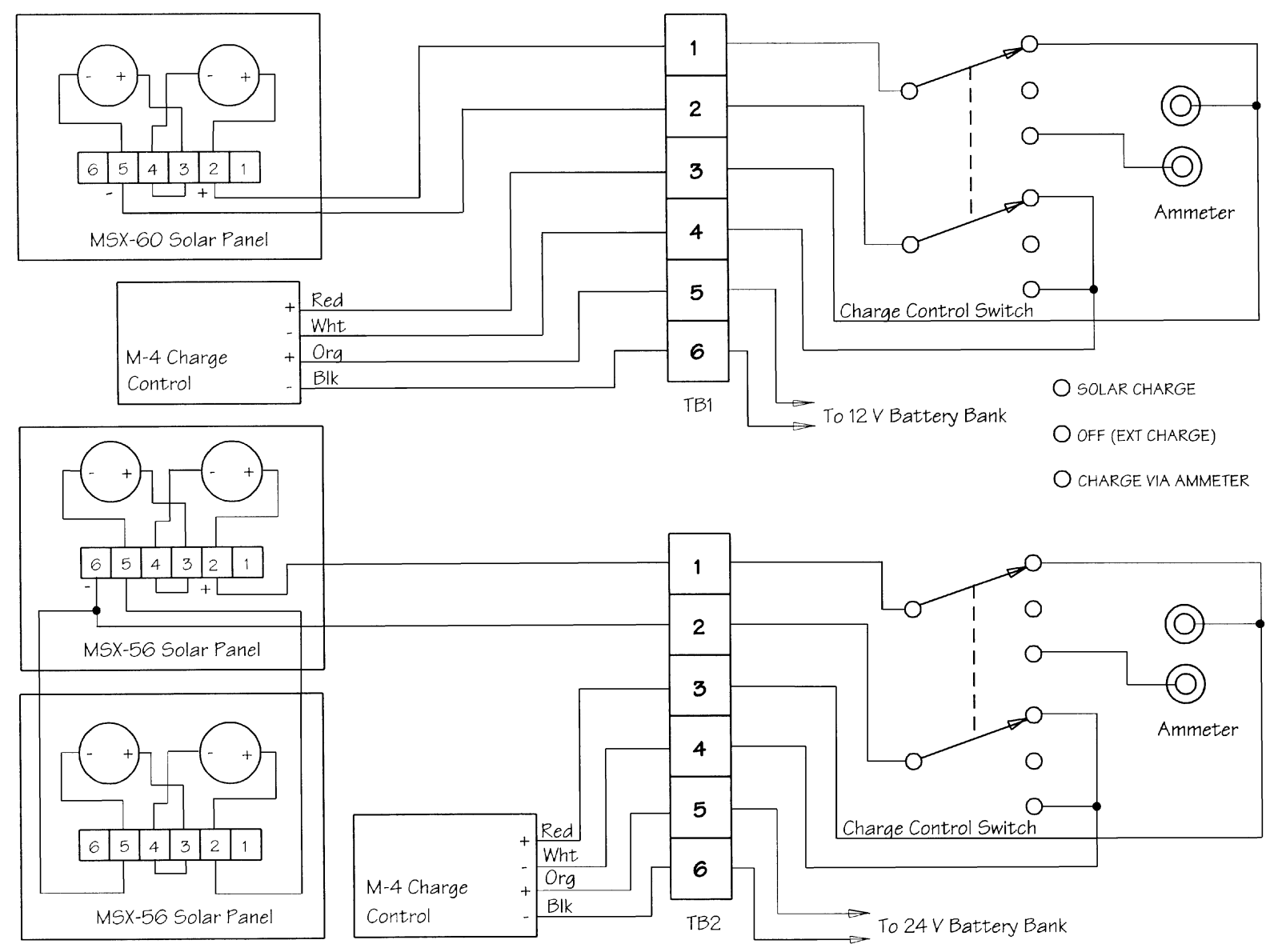

Figure 3. Charging control schematic diagram. 
type tank (designed for use in domestic well water systems). With a total volume of $326 \mathrm{~L} 86 \mathrm{gal})$, and while cycling between $140-$ and $280-\mathrm{kPa}$ (20- and 40-psi) charge pressure, the volume available for actual feed storage is about $120 \mathrm{~L}$ (32 gal). The storage tanks are filled at the barn using a progressing cavity pump driven by an AC motor. A progressing cavity pump is especially well suited for highly viscous liquids such as the molasses used in this project and can handle suspended solids as well. The use of a bladdertype tank has two advantages: (1) the energy required to move liquid from the storage tank to the feed bowl comes from the compressed air charge above the bladder; (2) the liquid is not exposed to air and therefore minimizes the moisture loss and associated clogging.

Liquid is metered by alternately energizing a pair of electrically operated air solenoid valves (fig. 4). When the solenoid valves are de-energized, air pressure at $414 \mathrm{kPa}$ (60 psi) is connected from a pair of 53-L (14-gal) air tanks to four Airpinch ${ }^{\mathrm{TM}}$ valves via a pressure regulator. When one of the solenoids is energized, the tank air supply is shut off and a pair of Airpinch ${ }^{\mathrm{TM}}$ valves is vented to atmosphere allowing feed to flow. The amount of feed delivered in each cycle is determined by the volume of the shuttle cylinder. As feed pressure is applied to one side of the cylinder, one cylinder volume of feed is forced out to the feed bowl. When the opposite solenoid is energized, the process repeats itself by opening the other pair of Airpinch ${ }^{\mathrm{TM}}$ valves and moving the shuttle in the reverse direction. The shuttle position is monitored with magnetic reed switches mounted on the outside of the cylinder wall. Magnets are embedded in the cylinder and actuate the reed switches when the shuttle slides in close proximity. This method of metering has advantages of very low electrical power consumption, highly repeatable amounts, and resistance to fouling by particles or by drying.

\section{Solid Feed Metering}

The need for feeding small quantities of pelletized or granular feeds has been met by providing two bins with approximately 40-kg (88-lb) capacity, each equipped with an auger-type metering assembly. Both assemblies are identical in design. The bins are recycled from cyclone dust collectors from New Holland grinder-mixers. A standard

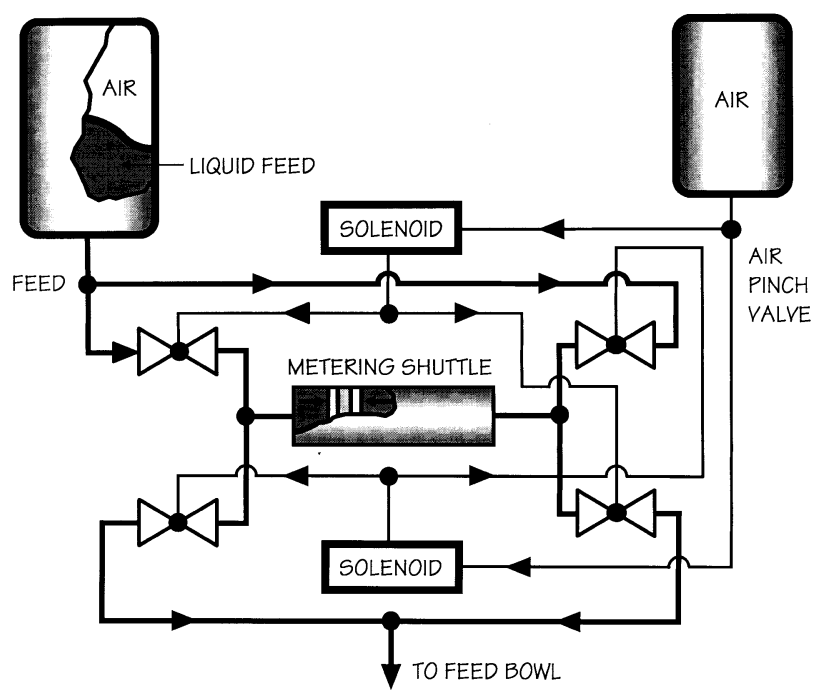

Figure 4. Liquid metering functional diagram. 2.5-cm (1-in.) auger-type wood-boring bit was used. The auger channel is made from $2.5-\mathrm{cm}$ (1-in.) Schedule 40 PVC inserted into a hole drilled through a $10-$ to 5- (4- to 2-in.) PVC adapter. The adapter provides a conical funnel that opens to the auger channel. The auger is driven by a small, permanent magnet DC gearmotor. The motor is rated for 12to 36-VDC input voltage and runs at approximately $70 \mathrm{rpm}$ with 24-VDC input. Motor revolutions are counted for control and data collection via an infrared (IR) emitter/detector assembly and a slotted disk mounted on the motor shaft. The slot in the disk passes through the emitter/detector once per revolution. The slot allows the IR emitter beam to pass to the detector, resulting in a single "on" pulse being sent to the PLC.

The largest feed storage unit provided on this feeder is the grain concentrate bin. The grain bin holds approximately $1.2 \mathrm{~m}^{3}\left(42.3 \mathrm{ft}^{3}\right)$ or about $900 \mathrm{~kg}(1984 \mathrm{lb})$. Grain output is metered by the use of a 5-cm (2-in.) auger running in an open 5-cm (2-in.) PVC channel at the bottom of the bin. Bin sides are sloped at 60 degrees and a wedge-shaped bin divider is mounted above the auger to minimize bridging. The auger is driven by a $12-\mathrm{V}$, permanent magnet DC gear motor rated for $6 \mathrm{rpm}$ at a full load torque of $56.5 \mathrm{~N} \cdot \mathrm{m}$ (500 in. $\mathrm{lb}$ ). Motor revolutions are counted for control and data collection via an infrared emitter/detector assembly and a slotted disk mounted on the motor shaft. Each $1 / 8$ revolution sends a single "on" pulse to the PLC.

\section{ANIMAL IDENTIFICATION}

An industrial, radio-frequency identification system, manufactured by Telsor Corporation (Englewood, Colo.) is used for animal identification. The system consists of a Model 5160 flat plate antenna with a Model 1840 sensor and Model 3030 interface and display unit. A Radio Shack PN 49-208 infrared sensor is used to switch the sensor between active and standby modes to conserve energy. Each animal carries a disc-shaped RF identification tag on the right ear. The tags measure $4 \mathrm{~mm}$ ( 0.16 in.) thick and $28 \mathrm{~mm}$ (1.1 in.) in diameter and weigh $8.5 \mathrm{~g}(0.3 \mathrm{oz})$. The RF tags are attached to an existing plastic ear tag using a nylon screw. Read range in this application is about $15 \mathrm{~cm}$ (5.9 in.). As an animal approaches the feed bowl, its head enters the range of the infrared sensor, and the tripped infrared sensor activates the tag reading system. Upon activation, an RF field is developed by the antenna that, in turn, supplies all necessary power to the tag. As the tag is energized, it transmits its programmed tag information to the sensor and interface unit via the same antenna. The interface then communicates with the PLC, which controls feed output based on the animal identification number and programmed feeding schedule.

\section{CONTROL}

All feeding functions are controlled by a central Programmable Logic Controller (PLC) (fig. 5). The PLC used on this feeder is an Aromat model FP1-C40C (Matsushita Electric Works, Ltd., Osaka, Japan). This PLC has 24 inputs and 16 outputs, runs on 24 VDC, contains a real time clock and calendar, has an RS-232c link for communication, and can store programs of up to 2720 steps. Programming is handled using software provided with the PLC and a special serial cable that connects to a personal computer. Programming can be done in either Boolean or ladder logic format and includes 


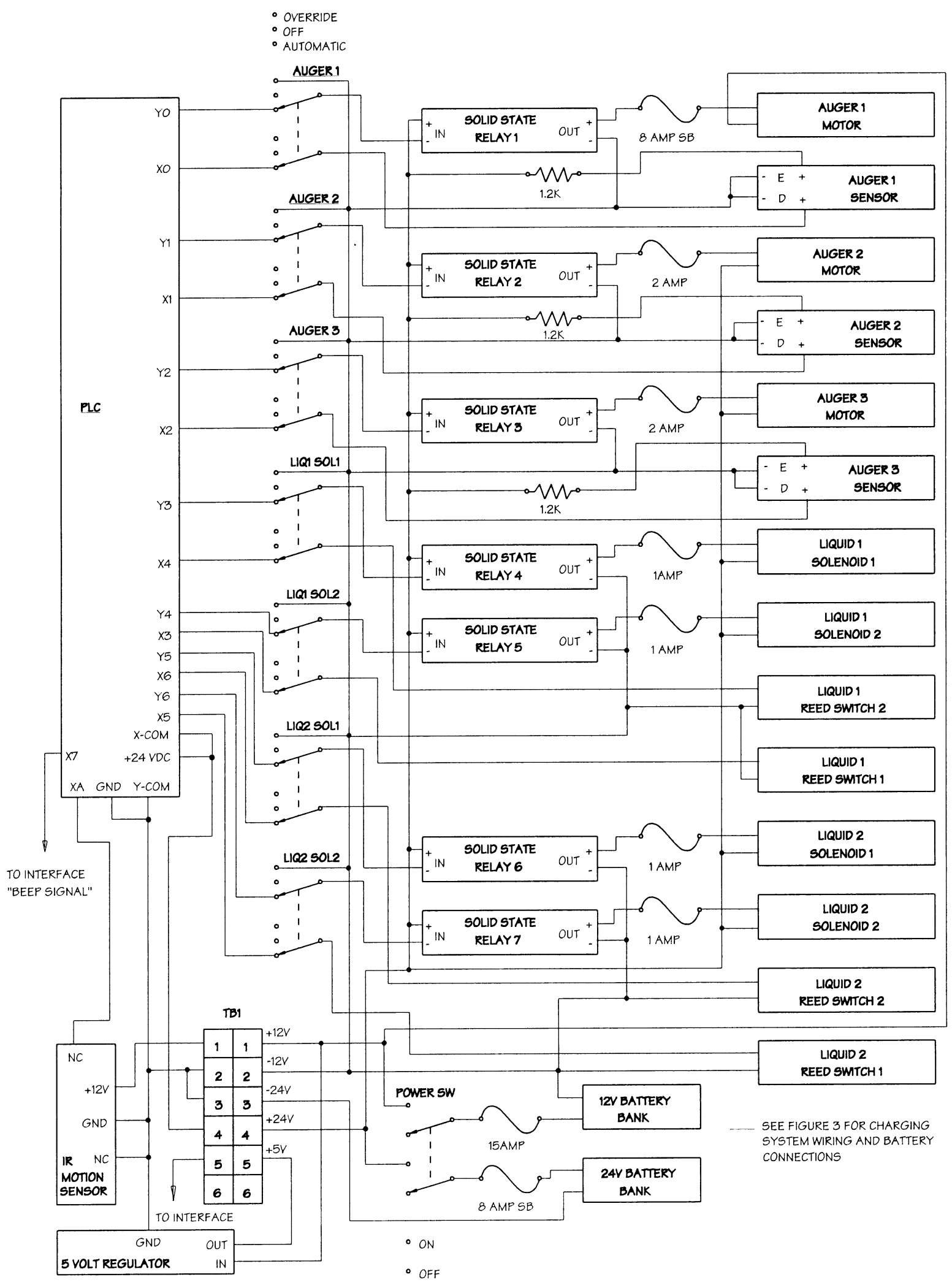

Figure 5. Control system schematic diagram.

commands for communication, logic, arithmetic, and data storage. Inputs are turned on by providing a ground to the input point. The outputs are transistor open-collector type which, when on, provide a ground path for loads up to $0.5 \mathrm{~A}$ per point. Since output current handled by the PLC is low, all loads are connected via solid-state relays. 


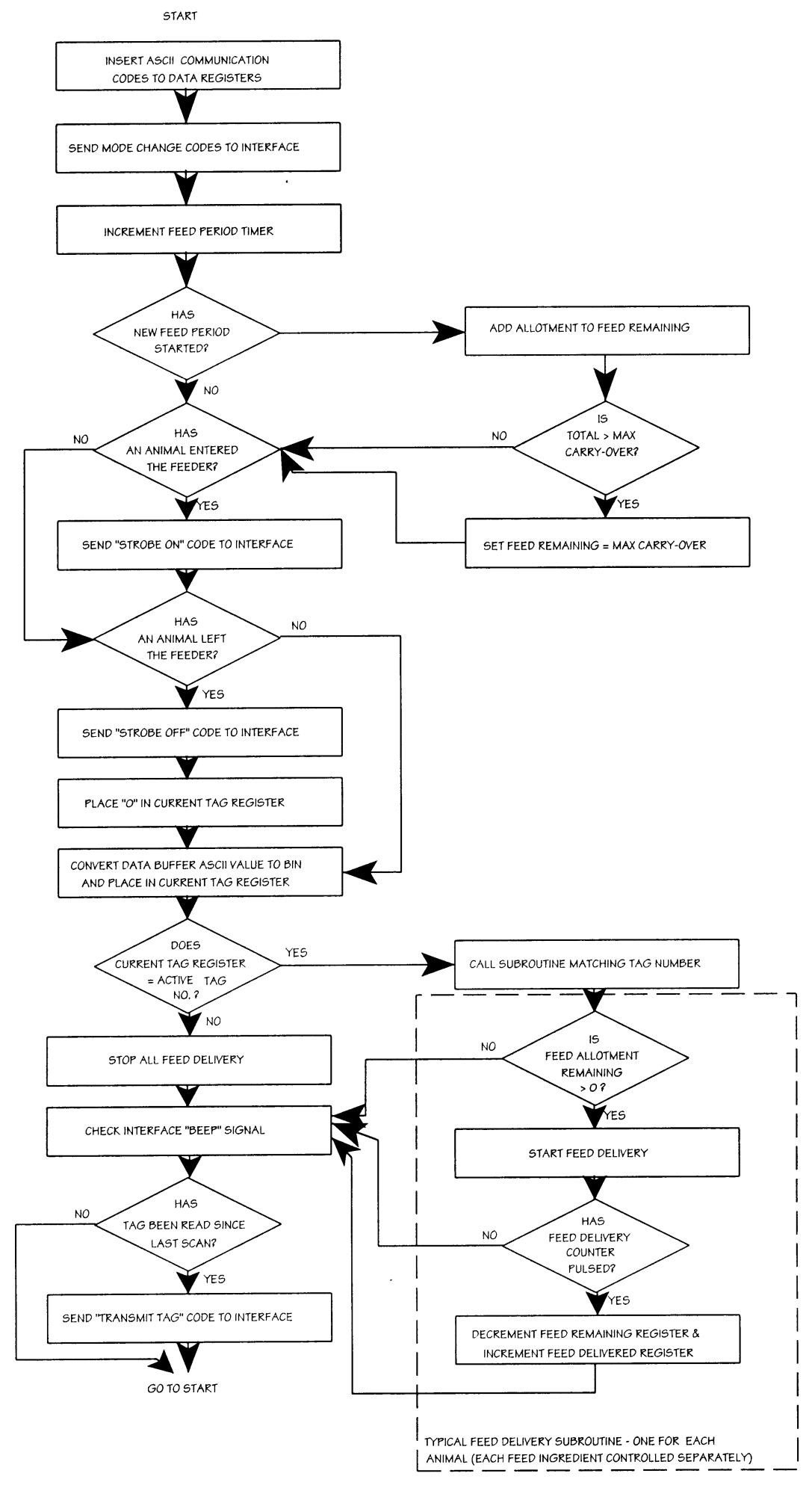

Figure 6. PLC program flow chart.

\section{Plc Program}

The PLC program's three major functions are communication with the tag reader, control of feed metering, and manipulation of feed data (fig. 6). When no animal is present at the feed bowl, the infrared motion detector mounted above the bowl entrance keeps the tag-reading antenna and sensor in a power-saving stand-by mode. When an animal's head enters the feed bowl enclosure, the PLC sends a "strobe on" signal to the interface unit via RS-232c link, which places the tag-reading system in the active mode. Upon de-energizing, the program keeps the reader active for $8 \mathrm{~s}$. If there is no movement at the motion detector, the PLC will transmit a "strobe off" signal and the tag reading system will remain in stand-by until animal motion is detected again. While the tag-reading system is in active mode, any tag passing within about $15 \mathrm{~cm}$ parallel to the antenna face will be energized and 
will transmit its programmed tag information through the antenna and sensor to the interface unit. A 2-s time delay between tag data requests from the PLC allows time for the interface to search for tags and the PLC to complete data transfer and conversions.

Once a tag number is present in the appropriate data register within the PLC, that tag number is compared to a list of all programmed tags. If the tag is a match, the program jumps to a subroutine that contains all instructions required to feed that animal. Each animal is assigned a separate subroutine that contains the addresses of data registers assigned to that animal. Whenever the motion detector input resets (no animal motion detected) the current tag number data is overwritten with a series of zeros. A zero tag number will not match the tag list, and therefore, feed delivery is cut off .

The program steps (as well as communications and input and output refreshing) run in a continuous loop called "cyclic execution." Each program execution cycle is referred to as one "scan." The scan time for the feeder test program was $7.5 \mathrm{~ms}$, with an absolute maximum scan time of $410 \mathrm{~ms}$ for the PLC. During each scan, the PLC checks the inputs for new data. Based on these input signals the program will update the appropriate data registers. Each animal is allocated three data locations for each feed ingredient. The first register is the allotted feed amount for a programmed feeding period, which the operator changes to modify the individual animal's ration. The second register contains the remaining feed available for the period. Each time a unit of feed is dispensed, a unit is subtracted from this register. The third data register represents the cumulative feed delivered to a given animal. This register is incremented each time a unit of feed is delivered, and does not reset automatically. It therefore can give a grand total of feed delivered to the individual over a period of days or more. The "feed allotted" and "feed remaining" registers are reset by the program. At the end of each programmed feeding period, the allotted feed quantity is added to the remaining feed quantity, and the result is compared to a maximum carry-over value. If the result is larger, the maximum carry-over value is inserted into the feed-remaining register. For example, suppose an animal has a $1-\mathrm{kg}$ allotment, $1 \mathrm{~kg}$ remaining, and the maximum carry-over is $1.5 \mathrm{~kg}$. The program would first add the $1 \mathrm{~kg}$ remaining to the $1-\mathrm{kg}$ allotment. Since the result is greater than $1.5 \mathrm{~kg}, 1.5 \mathrm{~kg}$ would be placed in the feed remaining register. Feed allotment can be changed by replacing the value located in the allotment register. Maximum carry-over is changed by replacing the constant in the comparison step of the program (each animal can have a different maximum carry-over). The number of feeding periods is changed by entering the desired feeding period constant in the appropriate line of the program. The tested program placed all animals on the same schedule, but the schedule could be modified easily to stagger feeding periods for subgroups within the herd.

\section{Evaluation AND Testing}

Testing and evaluation was completed in two phases. During in-lab testing, the rate of feed delivery, the incremental accuracy of feed delivery, and the electrical power consumption were recorded. The objective of the second phase of testing was to prove that the feeder would function in an actual animal trial in the pasture. Two groups of ten dairy animals were used to test the feeder. The first group, used in August, had eight two-year-old heifers and two cows. The second group, used in October, consisted of nine heifers and one cow. The programmed daily ration for each animal consisted of $5.0 \mathrm{~kg}(11.0 \mathrm{lb})$ of ground corn, $0.5 \mathrm{~kg}$ $(1.1 \mathrm{lb})$ of small-pelletized feed, and $0.2 \mathrm{~kg}(0.44 \mathrm{lb})$ of liquid molasses feed divided into two equal $12-\mathrm{h}$ feeding periods.

\section{Chassis}

Among the implicit objectives in building a feeder chassis are strength, stability, ease of use for both animals and operators, and weather protection. The completed feeder structure handled the weight of equipment and feed with no failures or undue flexing. Although no failure occurred, the top spacing bar at the entrance to the animal control gates proved to be too light in field trials (at least when animals of differing size are using the feeder). The gates were sized for the body of a full-grown Holstein cow. Since the heifers were considerably narrower and shorter in length, two animals would sometimes wedge themselves partly through the gate entrance resulting in slight bending of the top spacer bar and tubing of the gates themselves. The feeder was easily pulled by a small to medium-sized tractor and exhibited no stability problems in the field. Once the feeder was calibrated and programmed for the feeds being used, setting up the feeder was straightforward. The feeder needs only to be parked with the solar panels facing the sun, the gates unfolded and pinned into position, the wheels chocked, and the controls turned on. Calibration consisted of running out a fixed number of rotations or strokes and weighing the samples. Using the number of rotations and weight, it was a simple matter to determine the incremental feed weight and programming values. Since delivery is volume-based but feed mass is desirably controlled, calibration must be performed whenever the feed type or grind is changed. All areas requiring routine monitoring are easily accessible, although some climbing is necessary to visually check the three solid bin feed levels. The animals had no problems using the feeder and appeared to have a comfortable feeding position. The gates aligned the animals properly while keeping harassment by other cattle to a minimum.

\section{Electrical Power System}

Full-load current tests were performed on each of the electrical loads. Electrical power generation data as well as power consumption and solar irradiance data were recorded through the use of two Campbell CR10 dataloggers. Separate dataloggers were required for the $12-$ and $24-\mathrm{V}$ systems because the maximum differential input voltage of a single datalogger would have been exceeded. The dataloggers measured solar irradiance once every 10 seconds and recorded the average of each 5-min interval. A 5-min averaging and recording interval was also used for 12 and $24 \mathrm{~V}$ charging currents, however the dataloggers took measurements every $0.25 \mathrm{~s}$. Thirty-two days of solar and power-generation data were recorded for the $12-\mathrm{V}$ system and 28 days for the $24-\mathrm{V}$ system. These days were not consecutive and ranged from 20 July through 13 October. Average peak current over different days was about $1.4 \mathrm{~A}$ with an average peak solar irradiance of about $700 \mathrm{~W} / \mathrm{m}^{2}$ for 
the $12-\mathrm{V}$ system. Average current generation was $0.473 \mathrm{~A}$ for the $12-\mathrm{V}$ system with an average daily solar irradiance of $196 \mathrm{~W} / \mathrm{m}^{2}$. For the $24-\mathrm{V}$ system, average peak current generated was about $1.4 \mathrm{~A}$ and average current generation was $0.426 \mathrm{~A}$. Charge efficiency was highest when the battery was at a low state of charge or load demand was high. As battery voltage rises, the regulator pulses current to the battery to avoid gassing, prolonging battery life. The result is a lower average current output and an apparent lower charge efficiency. The last $10 \%$ of charging into the battery to reach full charge capacity is only about $33 \%$ efficient compared to nearly $100 \%$ efficiency for the first $90 \%$ of charge. The photovoltaic system easily handled the limited testing with 10 animals. Maximum capacity of the feeder is dependent primarily on the programmed ration, number of animals, condition of batteries, and weather. Variations in feeding strategy are virtually limitless, however, computer simulation of the electrical system indicates that it should handle typical supplemental feeding of up to 20 grazing dairy cows at a central Pennsylvania location (Thomas, 1996).

\section{LiQUid Metering System}

The liquid metering system functioned very well, delivering a molasses-based feed supplement accurately without clogging even after sitting idle for over three weeks with a full tank. Electrical current draw was $0.370 \mathrm{~A}$ at $24 \mathrm{~V}$ with an energized time of about $4 \mathrm{~s}$ per stroke. Volume calibration was performed by programming the controller to deliver 4 strokes per test cycle. A total of 35 test cycles were run (at approximately $24^{\circ} \mathrm{C}$ ) producing a mean feed mass of 393.5 or $98.4 \mathrm{~g}$ per stroke. Standard deviation for the four stroke test cycle was $1.79 \mathrm{~g}$. Feed delivery rate varied with tank pressure but was on the order of $5.9 \mathrm{~kg} / \mathrm{min}$. This rate seems high but the duration was very short and quantities small. Average rate of liquid delivery was controlled by inserting a time delay between strokes; this removed the effect of tank pressure.

The air supply used to operate the four Airpinch ${ }^{\mathrm{TM}}$ valves functioned without failure but required constant monitoring. Air consumption was higher than desirable due to leaks. Starting with a full $800 \mathrm{kPa}$ (115 psi) charge on both air tanks, only one of the two metering assemblies connected, and without feeding any liquids, the tanks would still drop below $410 \mathrm{kPa}(60 \mathrm{psi})$ in less than five days. During field testing, tanks had to be refilled every two to three days.

\section{SMall Solids Metering}

The small-solids metering system functioned flawlessly after an initial rainwater leak was corrected early in testing. Electrical current draw was $0.270 \mathrm{~A}$ at $24 \mathrm{~V}$ with a full load and turning at $69 \mathrm{rpm}$. Volume calibration was performed by programming the controller to deliver five auger rotations per test cycle. The mean feed mass determined from 35 test cycles was 23.2 or $4.64 \mathrm{~g}$ ( 0.818 or $0.164 \mathrm{oz})$ per auger revolution. Standard deviation for the five rotation test cycle was $1.34 \mathrm{~g}(0.0473 \mathrm{oz})$. Feed delivery rate was $320 \mathrm{~g} / \mathrm{min}$ (11.3 oz/min).

\section{Grain Metering}

The grain-metering system worked very well with initial problems caused primarily by a programming error. During initial field trials, the program malfunctioned twice causing the auger to turn continuously. As the grain filled and overflowed the feed bowl, the end of the grain chute was eventually covered causing the feed to clog in the pipe. The resulting forces were high enough to buckle the auger motor mount and shear the drive pin. After repairing the damage and correcting the program error, the grain metering system was problem-free in delivering the ground corn used for the trial. No grain bridging was observed during these trials.

Electrical current draw for the grain bin auger motor was $1.25 \mathrm{~A}$ at $12 \mathrm{~V}$ while delivering ground corn at $8 \mathrm{rpm}$. Volume calibration was performed by programming the controller to deliver three auger rotations per test cycle. A total of 35 test cycles were run producing a mean feed mass of 187.8 or $62.6 \mathrm{~g}(6.60$ or $2.20 \mathrm{oz})$ per auger revolution. Standard deviation for the three-rotation test cycle was $4.32 \mathrm{~g}$. Feed delivery rate was $500 \mathrm{~g} / \mathrm{min}(17.6 \mathrm{oz} / \mathrm{min})$.

\section{Animal IDENTIFICATION}

The animal identification system worked flawlessly. There was a concern early in the project that head placement and tag read range might limit the system's ability to identify the animal. In actual field operation these concerns were quickly dismissed. Tag read range was approximately $15 \mathrm{~cm}$, which proved to be more than adequate. Head placement and resulting tag orientation proved to be nearly ideal with the system tolerating more head movement than expected. Other tag systems used on the test animals in the parlor did not interfere with feeder operation. Reading accuracy was not tested since the manufacturer claims an error rate of only 1 in $1 \times 10^{14}$ reads.

While tag reading was problem free, the method of animal tagging had one failure in the form of tag loss. The ID tags were attached to an existing ear tag using a nylon screw and nut to avoid interference with the RF fields generated by the antenna and tag. The entire tag assembly fell out of one ear.

\section{ConTrol System}

After several modifications to animal detection methods, the system was problem free. The first arrangement used in the field trials had two gates for detection of animal presence. The first gate was hung from the spacer bar at the entrance to the animal control gates. Upon entrance, the gate would swing up and rest on the back of the animal. A mercury switch on the gate was connected to the PLC and was used to switch the tag reading system between stand-by and active modes. The gate concept worked well for fully-grown cows but the gate would slip down behind the smaller heifers. The gate also became the center of unceasing interest and play for the cattle. For these reasons, the swinging entrance gate was eliminated. The second gate was used to turn off feed flow as the cow removed its head from the feed bowl. As the animal lowered its head to the feed bowl, its neck would swing a lexan gate and actuate a limit switch riding on a cam. The gate worked fine, but was eliminated for two reasons. With the gate in use, it was only necessary to read a tag once. The tag number was retained until the animal passed out of the swinging entrance gate. The system was designed this way due to a lack of confidence in the unproven tag reading arrangement. The tag reading system proved reliable enough that successful animal ID could be counted on each time the head was lowered to the feed bowl. With consistent tag 
reading, the gate was unnecessary. The gate was also a moving part and therefore would eventually be a maintenance item. The final design, using the infrared motion detector, operated without problems.

\section{Plc Program}

The program proved to be the most problematic element in the feeder design (due mostly to our inexperience). Since the program controlled nearly all operations on the feeder, it was critical for proper operation. Program errors were ultimately responsible for early failures in the grain delivery system. When errors were corrected, the program functioned acceptably. Feed quantities were tracked and correctly delivered on schedule to the appropriate animals.

Feed delivery was controlled in an open loop. The feed was metered based on a number of strokes or auger rotations. The stroke and revolution count was fed back to the PLC but the actual feed was not weighed. This method proved acceptable since the feed quantity delivered was repeatable (coefficient of variation was $0.45 \%$ for liquids, $5.8 \%$ for small solids, and $2.3 \%$ for large solids) and the system was not susceptible to clogging.

\section{ANIMAL BeHAVIOR}

In general, the animals adapted to the feeder more quickly than anticipated. At the start of the trial, an "animal training" program was written for the PLC. The program gave a very small feed ration to the animal each time it passed through the gate entrance with no limit to the number of times it could leave and return. The purpose was twofold. First, since the feed would begin to flow while the animal was still at the entrance, it was thought that this would encourage the animal to put its head down into the feed bowl. Second, it was thought that numerous small feedings would encourage use of the feeder through positive reinforcement. In reality, it caused more problems than it solved. It enticed a few of the more dominant animals to monopolize the feeder. Since they were always rewarded, it may have encouraged their aggressive behavior. Using the actual feeding program, their feed allotment would eventually run out until the next feeding period thus making their aggressive behavior unrewarding. The special training program was not effective and would likely be unnecessary in future trials. The animals were best trained to use the feeder simply by running some feed into the bowl and waiting for a curious individual to take advantage of it. By the second day, $40 \%$ of the animals used the feeder and within four days, $70 \%$ were regularly using the feeder on their own. A few of the "shy" individuals were led into the stall and presented with feed. In every case, the animals returned after one successful feeding session.

\section{Conclusions ANd Recommendations}

Objectives for the project were: (1) to design, construct, and evaluate a mobile feeder with high enough efficiency to be operated without the need for AC power in the pasture; and (2) to develop the capability to meter liquids (including molasses), very small quantities of specialized feed supplements, and grain concentrates. The feeder resulting from this work operated with high enough efficiency to eliminate the need for AC power in the pasture. Liquids, grains, and small specialized solids were all metered accurately and consistently based on an individual animal program.

It is recommended that a fail-safe liquid shutoff be added to the liquid metering system. The Airpinch ${ }^{\mathrm{TM}}$ valves opened with a loss of air pressure. If the pressure differential between the compressed air and liquid feed dropped to less than 138 $\mathrm{kPa}$ (20 psi), the entire contents of the liquid storage tanks would empty into the feed bowl and onto the ground. A possible solution to this problem would be to add a pressure switch to the air system and pinch valve to the output tubing. Upon loss of air pressure, the switch would activate a solenoid-driven trip mechanism, which would pinch off the output tubes and stop flow.

\section{REFERENCES}

Albright, J. L. 1993. Feeding behavior of dairy cattle. J. Dairy Sci. 76(2): 485-498.

Earley, A. V., B. F. Sowell, and J. G. P. Bowman. 1999. Liquid supplementation of grazing cows and calves. Anim. Feed Sci. and Technol. 80(3/4): 281-296.

Gardner, M. O., D. R. Buckmaster, and L. D. Muller. 1995. Development of a mobile computer-controlled concentrate feeder. Applied Engineering in Agriculture 11(6): 785-790.

Hoffman, K., L. D. Muller, S. L. Fales, and L. A. Holden. 1993. Quality evaluation and concentrate supplementation of rotational pasture grazed by lactating cows. J. Dairy Sci. 76(9): 2651-2663.

Hongerholt, D. D., L. D. Muller, and D. R. Buckmaster. 1997. Evaluation of a mobile computerized grain feeder for lactating cows grazing grass pasture. J. Dairy Sci. 80(12): 3271-3282.

Leaver, J. D. 1982. Grass height as an indicator for supplementary feeding of continuously stocked dairy cows. Grass and Forage Sci. 37(4): 285-290.

Livshin, N., E. Malz, and Y. Edan. 1995. Regularity of dairy cow feeding behavior with computer-controlled feeders. J. Dairy Sci. 78(2): 296-304.

Mayne, C. S. 1991. Effects of supplementation on the performance of both growing and lactating cattle at pasture. In Grazing, Occasional Symp. No. 25. Br. Grassl. Soc. J. Frame ed., 55-71. Hurley, Berkshire UK: The Society.

Muller, L. D. 1993. Nutritional supplementation and ration balancing for high producing cows. In Occasional Publication No. 1, Improving the Quality and Intake of Pasture-Based Diets for Lactating Dairy Cows. Department of Agricultural and Horticultural Systems Management. Massey University, New Zealand.

Pitt, R. E., and A. N. Pell. 1997. Modeling ruminal pH fluctuations: interactions between meal frequency and digestion rate. J. Dairy Sci. 80(10): 2429-2441.

Shrestha, C. M., S. L. Spahr, H. B. Puckett, and E. F. Oliver. 1983. Electronic transponder feeder system performance and animal feeding behavior with four feed availability times. J. Dairy Sci. 66(2): 332-340.

Soder, K. J., and C. A. Rotz. 2001. Economic and environmental impact of four levels of concentrate supplementation in grazing dairy herds. J. Dairy Sci. 84(11): 2560-2572.

Stockdale, C. R., A. Callaghan, and T. E. Trigg. 1987. Feeding high energy supplements to pasture fed dairy cows. Effects of stage of lactation and level of supplement. Aus J. Agric. Res. 38(5): 927-40.

Stockdale, C. R., R. Currie, and T. E. Trigg. 1990. Effects of pasture and supplement quality on the responses of lactating dairy cows to high energy supplements. Aus. J. Exp. Agr. 30(1): 43-50.

Thomas, R. S. 1996. A programmable, multiple supplement cattle feeder for pasture use. M.S. thesis. The Pennsylvania State University. University Park, Pa. 
Weber, G. M. 1989. Electronic identification of cattle for evaluating and marketing. In Proc. 1989 Beef Improvement Federation Annual Conv., 7-12. Stillwater, Okla.: Beef Improvement Federation. 